\title{
Simulation of the Electrical Parameters of Organic Photovoltaic Cells under QUCS and GPVDM Software
}

\author{
OURIDA OURAHMOUN \\ Electronic Department \\ University of Mouloud MAMMERI of Tizi-Ouzou \\ BP 17 RP 15000, Tizi-Ouzou \\ ALGERIA
}

\begin{abstract}
Polymer solar cells have attracted much attention during the last years due to their lower fabrication cost and possibility of using flexible substrates. Various parameters contribute to the stability of the performances of organic solar cells: the configuration or the structure of the cells, the materials used in their elaboration such as the active layer, the hole transport layer, the electron transport layer and the electrode contact. This work represents the modelling and simulation of organic solar cells using two software: Quite Universal Circuit Simulator, QUCS and General-Purpose Photovoltaic Device Model, GPVDM. First, an equivalent circuit model constituted from one diode, a series and shunt resistance, and a photocurrent generator have been used, this circuit is simulated under QUCS. The simulated results as function of different parameters such as series resistance, temperature of the cell, the ideality factor and current saturation are given. The current density as function of voltage $\mathrm{J}-\mathrm{V}$ characteristics of the organic cell obtained from the experimental results are compared to the simulated one, results show that the curve with $\mathrm{Rs}=10 \Omega$ correspond to the experimental one, the ideality factor obtained by simulation of the organic cell is 1.2 , which corresponds to recombination assisted by the traps levels. Second, we discuss the different structures of organic solar cells and the role of the interface layer used as hole transport layer or electron transport layer. The effect of the thickness and the type of the interfacial layers is simulated under GPVDM. The best efficiency is obtained in the case of cell using aluminum-doped zinc oxide $(\mathrm{AZO})$ as electron transport layer and copper oxide $\left(\mathrm{Cu}_{2} \mathrm{O}\right)$ as hole transport layer. The optimized cell is of the type: ITO/AZO $(40 \mathrm{~nm}) / \mathrm{P} 3 \mathrm{HT}: \mathrm{PCBM}(200 \mathrm{~nm}) / \mathrm{Cu}_{2} \mathrm{O}(20 \mathrm{~nm}) / \mathrm{Ag}$, with a best power conversion efficiency of $5 \%$.
\end{abstract}

Key-Words: - Organic solar cells, temperature effect, ideality factor, simulations, QUCS, Interface materials, GPVDM

Received: April 18, 2020. Revised: August 29, 2020. Re-Revised: September 14, 2020. Accepted: September 27,

2020. Published: October 5, 2020

\section{Introduction}

The Organic Solar Cells (OSCs) have attracted great attention due to their easy solution-processed preparation and material tunability, which could lead to light-weight, low-cost and large-area flexible solar products. Despite the shortcomings of their inferior device stabilities, their power conversion efficiencies (PCE) grow quickly with the development of new materials, and have surpassed $12 \%$ recently. Polymer solar cells have attracted much attention during the last years due to their lower fabrication cost and possibility of using flexible substrates [1]. However, their efficiency is usually less than $5 \%$. The active layer morphology related to blending preparation and annealing [2], is one of the most important factors affecting solar cell efficiency. Organic solar cells undergo many degradation pathways during their lifetime [3]. Efficiency loss is due to light, oxygen and water. The exposure to oxygen leads to enhanced charge carrier concentration and a decreased charge carrier mobility. A lower mobility leads to a higher extraction time for the charge carriers and therefore to an enhanced bimolecular recombination probability which results in decreased FF. The open circuit voltage is slightly increased because the Langving recombination rate is lower when the mobility decreased. The higher charge carrier densities reduce the internal field and therefore increase the open circuit voltage. Thermal annealing improves cell efficiency [4].

Various parameters contribute to the stability of the performances of organic solar cells. The 
configuration or the structure of the cells, the materials used in their elaboration such as the active layer the electrode contact and the interfacial materials [5]. The current density depends in temperature, the mobility of carrier charges, and substrate type. Thermal annealing reduces interface defect, and increases crystallinity which improves the mobility of carriers then improves photocurrent. Several factors contribute to increase the series resistances when the device is left in ambient conditions such as reduction of mobility, metal corrosion at the contact or changes in the contact barrier and charge space regions.

In this work, structure and fabrication method of inverted organic solar cells are presented.

There is urgent need to improve the device performance using better designs, technologies and models. The current-voltage characteristics of organic solar cells (OSC) is analyzed in terms of equivalent lumped parameter circuit at different level of insolation. In particular, starting from a circuital model based on a three-diode configuration, a set of formulas is proposed to describe the dependence of lumped circuit al parameters on irradiance intensity and consequently the behavior of organic solar cells from dark to high irradiance conditions [6]. A new one-equation model based on a generalized equivalent circuit capable of accurately fitting ideal and nonideal curves [7]. To explain the S-shape currentvoltage curves found in some experimental data a model is used [8]. A simple and versatile electrical model for plasmonic solar cells is proposed [9]. A numerical model that includes the 3D morphology of the blend in the simulator is developed. The model able to observe the charge and current density distribution across the blend at different working points. The effect of charge unbalance to solar cells performance is investigated [10]. Response surface methodology (RSM) is used to find optimal fabrication conditions for polymer solar cells. In order to optimize cell efficiency, the central composite design (CCD) with three independent variables polymer concentration, polymer-fullerene ratio, and active layer spinning speed was used. The variation in the device performance was explained by the best model. The experimental results are consistent with the CCD prediction, which proves that this is a promising and appropriate model for optimum device performance and fabrication conditions [11]. A Kinetic Monte Carlo model was developed to simulate the morphological variation of organic solar cells and its effects on photovoltaic parameters. This model is currently based on P3HT: PCBM system and can be easily extended to any low bandgap polymer solar cells. Other models can simulate three different parameters including domain size, donor-acceptor ratio and active layer thickness in the same model and predict the efficiency of organic solar cells on the variation of these parameters [12]. The microscale model consists of a system of partial and ordinary differential equations in an heterogeneous domain, that provides a full description of excitation/transport phenomena occurring in the bulk regions and dissociation/recombination processes occurring in a thin materials across the interface, the device performance is determined not only by the total interface length but also by its shape [13]. A mathematical model for OSCs consists of a system of nonlinear diffusion-reaction partial differential equations (PDEs) with electrostatic convection, coupled to a kinetic ordinary differential equation (ODE) is described [14]. The optical wave propagation in the 3D solar cell is simulated by Finite Difference Time Domain simulations. The influence of the nanowire dimensions on the quantum efficiency and short circuit current density of the solar cells is discussed, 3D model of solar cell allows for decoupling of electrical and optical properties [15]. Several models predict power conversion efficiencies in the range of $10-15 \%$. A more general approach assuming device operation close to the ShockleyQueisser-limit leads to even higher efficiencies [16]. A novel building-block approach to equivalent circuit modelling of organic photovoltaic cells capable of simulating both optimal and degraded devices has been developed [17]. The polaron-pair recombination are presented by an internal shunt resistance in the equivalent circuit model [18]. The origin of $\mathrm{S}$ shape curve through an improved equivalent circuit model (ECM) is giving. The improved ECM involves a D:A junction as well as a rectifying junction to interpret the bias-dependent-recombination [19].Two real models (single-diode and double-diode) are studied $[20,21,22]$. A fast and accurate method through utilizing combined analytical and numerical approach to determine the five parameters double diode model of photovoltaic modules is proposed. A rapid and accurate iterative numerical method is proposed to determine the value of series resistance. The proposed model can be useful for PV designers who require a fast, accurate and simple approach for modeling the PV modules [23, 24]. Factors that dominate the junction diodes in OSCs are discussed and suggestions for optimizing the junction diodes are 
proposed [25, 26]. A novel explicit model is proposed to represent I-V expression of conventional doublediode model for photovoltaic (PV) cells. This model is based on two rules [27]. A simulation study indicates that the conduction mechanism in the organic solar cell is strongly influenced by the excitonic diffusion. The performance of the opv device can be described by a two-diode-equivalent model [28]. The opposed two-diode equivalent-circuit model consisting of a traditional one-diode photocell model and a parasitic diode with a parallel resistance is known to some how reproduce the S-shaped current-voltage curve of poor organic photocells [29]. S-shape, in the current-voltage $(I-V)$ characteristics, has been attributed to different physical phenomena such as poor quality of cathode-active layer interface or unbalance charge carrier mobilities. This non-ideal behavior can be electrically modelled including a second diode, in reverse bias, together with an extra shunt resistance in the traditional solar cell equivalent circuit [30]. Light activation phenomenon in inverted bulk heterojunction (BHJ) organic solar cells (OSC) has been electrically modelled with a two-diode equivalent circuit. Current-voltage (I-V) characteristics show a highly pronounced S-shape that is gradually removed during light activation process. The circuit used to model $I-V$ curves includes two diodes in forward and reverse bias together with two parallel resistances. The parallel of the reverse bias diode and its corresponding resistance models the electrical behaviour of the interlayer and photoconductivity are presented $[31,32,33]$. There are numerous studies that develop the mathematical modeling of photovoltaic cells and verified by software: Matlab ; 1D Amps, PC1D, matrix transfert scaps-1D and General Purpose Photovoltaic Device Model (GPVDM). The model presented in this work is based on an equivalent circuit implemented in free software, Quite Universal Circuit Simulator (QUCS). QUCS uses a generic diode for adjust the current and voltage I(V) curve at photovoltaic cell. Additionally, we can use equations to define the model of photovoltaic cell and represent its characteristic curves. The model of PV cell can be used to simulate a PV module, because PV module is an association of cells in serie and parallel.

In this study, a single diode model used to simulate organic photovoltaic cells is proposed. The simulated results are compared to the experimental one. The structure of the cell simulated is glass/ITO/ETL/active layer/HTL/Ag, ETL: electron transport layer, HTL: hole transport layer, the active layer is a mixture of an acceptor and donor organic materials.

To show the effect of the thickness of the different layers on the performances of the inverted organic solar cells, GPVDM software is used. Results shows that the use of aluminumdoped zinc oxide (AZO) as ETL and molybdenum oxide $(\mathrm{MoO} 3)$ or copper oxide $\left(\mathrm{Cu}_{2} \mathrm{O}\right)$ as HTL gives better performances.

\section{Structure of the organic photovoltaic cells}

The structure of the cells realized is glass/ITO/ZnO/P3HT:PCBM/Pedot/Ag. The structure is presented in Figure 1. Zinc oxide $(\mathrm{ZnO})$ is used as electron transport layer (ETL). Pedot is used as a hole transport layer (HTL), Poly(3-hexylthiophene) (P3HT) as donor and Phenyl-C61-butyric acid methyl ester (PCBM) as acceptor. The $\mathrm{J}(\mathrm{V})$ characteristics of the cells, with area $0.18 \mathrm{~cm}^{2}$, are measured in the dark and under light intensity $\left(100 \mathrm{~mW} / \mathrm{cm}^{2}\right)$. Figure 2 shows current density and power characteristics as function of voltage, $V_{O C}$ is the open circuit voltage. The measured parameters of the cell are shown in table 1.

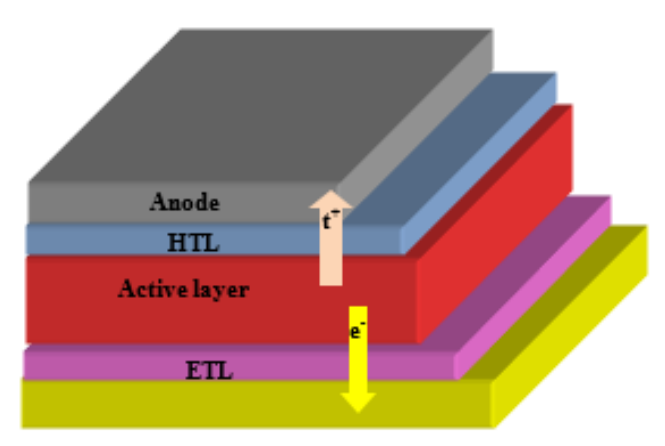

Fig. 1. Structure of the organic cells.

\subsection{Fabrication of the inverted organic photovoltaic cell}

The inverted bulk-heterojunction (BHJ) solar cell is based on a blend of Poly(3-hexylthiophene-2,5diyl) (P3HT) and [6,6]-Phenyl C61 butyric acid methyl ester (PCBM). The glass substrate covered by transparent electrode of indium tin oxide (ITO) with sheet resistance of $7 \Omega$ /square was ultrasonically cleaned in acetone, ethanol and isopropanol for $10 \mathrm{~min}$ respectively, then treated 
by UV ozone for 10 min afterwards, nanoparticles of zinc oxide ( $\mathrm{ZnO} \sim 40 \mathrm{~nm}$ thick) was spin coated on the substrate in order to form an electron transport layer. Having been dried at $130{ }^{\circ} \mathrm{C}$ for 15 min a film ( $200 \mathrm{~nm}$ thick) of the blend of P3HT:PCBM with a weight ratio of (1:0.8) in 1-2 dichlorobenzene was further spin coated on $\mathrm{ZnO}$. This active layer was covered with $\operatorname{Poly}(3,4-$ ethylenedioxythiophene)- poly(styrene sulfonate) PEDOT (F010) ( $40 \mathrm{~nm}$ thick), this layer is used as a hole transport layer. Finally, an Ag electrode was evaporated at $10^{-6}$ mbar (100 $\mathrm{nm}$ thick) through a shadow mask delimiting a $0.18 \mathrm{~cm}^{2}$ solar cell area. The cells are annealed at $110{ }^{\circ} \mathrm{C}$ for $30 \mathrm{~min}$ in the glove box. The $\mathrm{J}(\mathrm{V})$ characteristics of the cells are measured in the glove box. A power conversion efficiency (PCE) of $4.22 \%$, open circuit voltage $\left(\mathrm{V}_{\mathrm{OC}}\right)$ of $0.59 \mathrm{~V}$, short current density $\left(\mathrm{J}_{\mathrm{SC}}\right)$ of $11.02 \mathrm{~mA} / \mathrm{cm}^{2}$ and fill factor (FF) of $65 \%$ are achieved as shown in Figure 2.

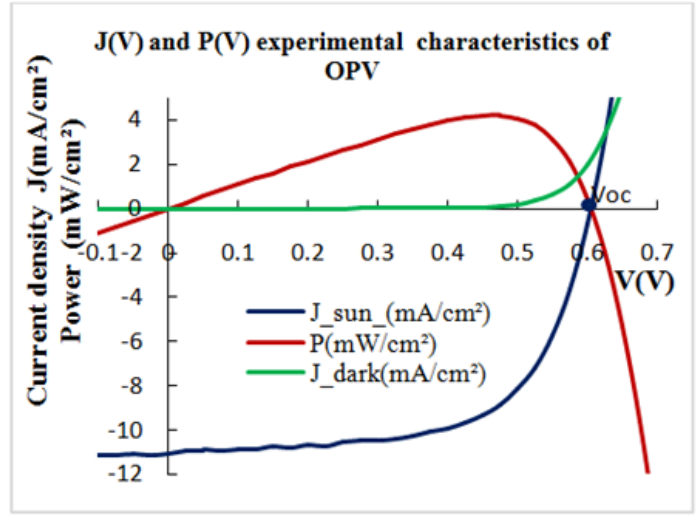

Fig. 2. Experimental $J(V)$ and $P(V)$ characteristics of inverted organic solar cells.

TABLE I: Experimental parameters of the organic solar Cells

\begin{tabular}{llllll}
\hline \hline $\begin{array}{l}\mathrm{V}_{\mathrm{OC}} \\
(\mathrm{V})\end{array}$ & $\begin{array}{l}\mathrm{J}_{\mathrm{SC}} \\
\left(\mathrm{mA} / \mathrm{cm}^{2}\right)\end{array}$ & $\begin{array}{l}\eta \\
(\%)\end{array}$ & $\begin{array}{l}\text { Rs } \\
(\%)\end{array}$ & $\begin{array}{l}\text { Rsh } \\
(\Omega)\end{array}$ & $(\Omega$ \\
\hline 0.59 & 11.02 & 65 & 4.22 & 39.54 & 3731.15 \\
\hline \hline
\end{tabular}

\section{Simulation of the organic solar cells using Qucs simulator}

\subsection{Equivalent circuit model used under QUCS}

The circuit equivalent to a single diode used to model the electrical behavior of a photovoltaic cell based on P3HT: PCBM under QUCS is shown in Figure 3. This diagram allows us to compare the results obtained by experimental measurement with simulation results. By modifying the parameters of the circuit we can get closer to the experimental curves of the cell. The model works according to Schockley's equation. By introducing the experimental parameters of the cell into the model we obtain the desired characteristics.

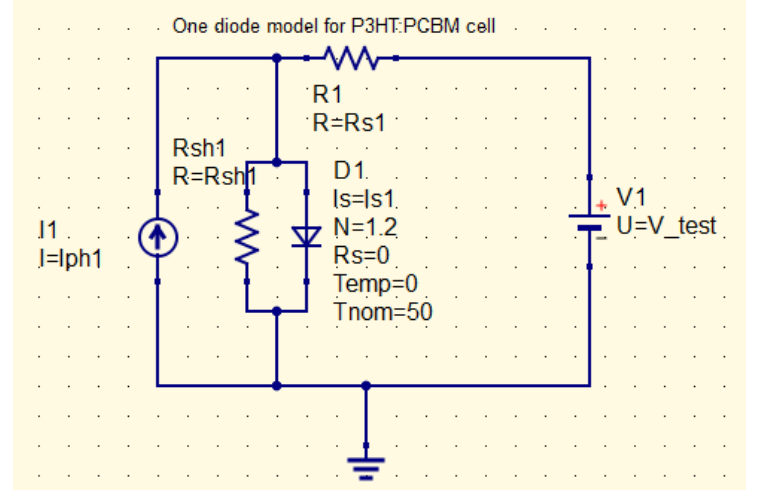

Fig. 3. Equivalent circuit model used under QUCs simulator.

\subsection{Equations of the Model}

The current of the diode is given by the equation (1). Where I is the output current of the photovoltaic cell, $\mathrm{I}_{\mathrm{ph}}$ is the photocurrent generated, $\mathrm{I}_{0}$ is the saturation current, $R_{S}$ is a series resistance due to junction between the semiconductor and the metal contacts, $\mathrm{R}_{\mathrm{sh}}$ is parallel resistance due to the linearity of the PN junction, $\mathrm{n}$ is the ideality factor of the diode, $\mathrm{k}_{\mathrm{B}}$ is the Boltzmann constant, e is the elementary charge of electron and $\mathrm{T}$ is temperature in Kelvin.

$$
I=I_{p h}-I_{0}\left(\exp \left[\frac{e\left(V+I R_{S}\right)}{n k_{B} T}\right]-1\right)-\frac{V+I R_{S}}{R_{S h}}
$$

The short circuit current $\mathrm{I}_{\mathrm{SC}}$ is given using the equation (2). 


$$
I_{S c}=I_{p h}-I_{0}\left(\exp \left[\frac{e I_{s c} R_{S}}{n k_{B} T}\right]-1\right)-\frac{I_{S c} R_{S}}{R_{S h}} \approx
$$

The open circuit voltage $V_{\text {oc }}$ is giving by equation (3).

$$
V_{o c}=\frac{n k_{B} T}{e} \ln \left[1+\frac{I_{p h}}{I_{s}}\right]
$$

The conversion efficiency of organic cells depends on the solar cells surface, as given in equation (4). The dependence of the parameters of the organic cells as a function of the cell surface can be simulated using equation (4).

$$
\eta=F F \frac{V_{o c} \frac{I_{S c}}{S}}{\phi}
$$

Where $\mathrm{V}_{\mathrm{OC}}$ is the open circuit voltage, $\mathrm{I}_{\mathrm{SC}}$ the short circuit current, $\phi=1000 \mathrm{~W} / \mathrm{m}^{2}$ the standard power irradiation by square meter, $\mathrm{S}$ the solar cell surface and $\mathrm{FF}$ the fill factor.

\subsection{Simulation of the temperature effect}

In the laboratory when characterizing the organic cell, the cell is exposed to the radiation of the simulator which causes its heating, the temperature of the cell can increase up to $70^{\circ} \mathrm{C}$. This thermal energy has effects on the transport of charges, on the photocurrent generated, on the internal potential and on the total current of the organic cell. The influence of temperature on the performances of the cell appears in the current equation by the term $\mathrm{V}_{\mathrm{T}}\left(\mathrm{V}_{\mathrm{T}}=\mathrm{k}_{\mathrm{B}} \mathrm{T} / \mathrm{q}\right)$ which represents the thermal potential; this potential represents the thermal agitation of the charges in the medium under consideration. Figure 4 shows the influence of temperature on I (V) characteristics of the cell, the results obtained by simulation. When the temperature increases the open circuit voltage $V_{O C}$ decreases and the short circuit current density $\mathrm{J}_{\mathrm{SC}}$ remains almost constant. The power generation of the organic cells as function of temperature is shown in Figure 5. The power generation decreases when temperature increases.

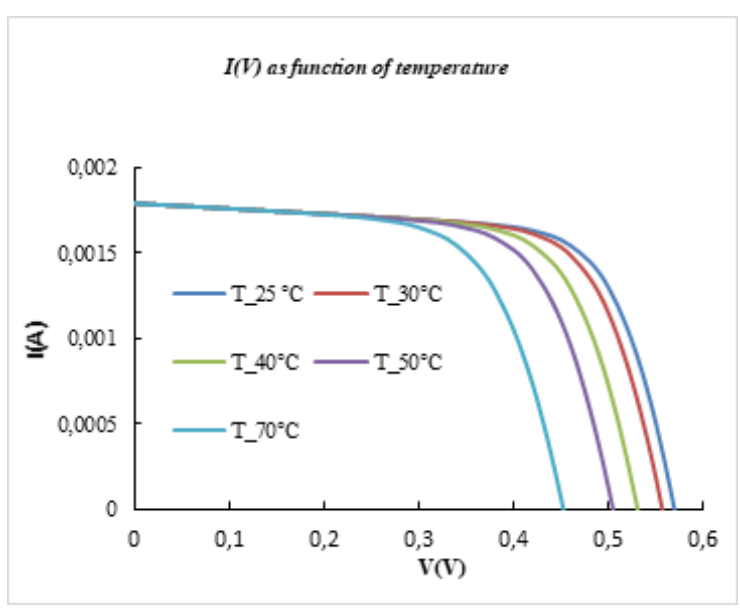

Fig. 4. Simulation of $I(V)$ characteristics as a function of diode temperature.

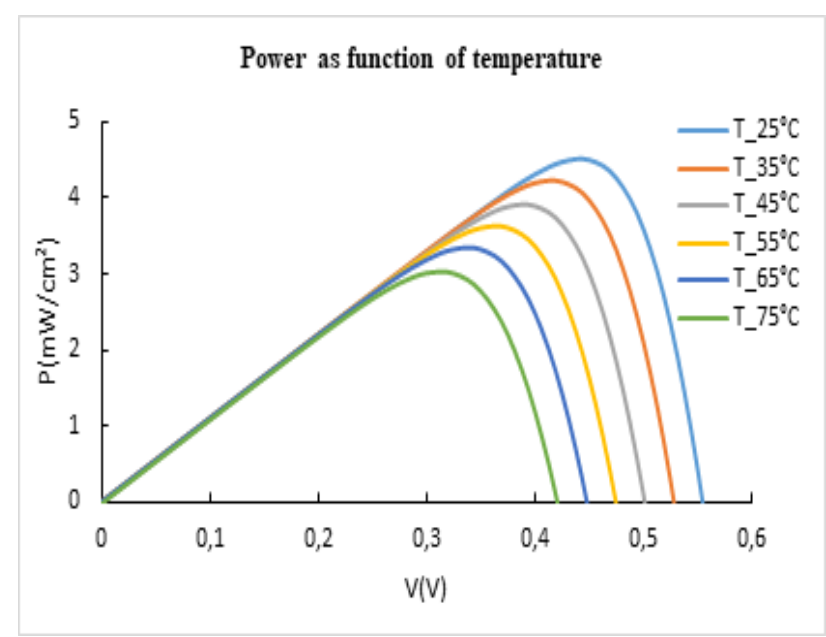

Fig. 5. Simulation of the power generation of the cell as function of temperature.

\subsection{Effect of the ideality factor}

In a silicon solar cell, the ideality factor $\mathrm{n}$ is considered equal to 1 , which means that the recombination is band-band type, while in the organic cells it is considered to be close to 2, which corresponds to recombination assisted by the traps levels. From the experimental curves, we can still estimate an ideality factor by deriving the logarithm of the current of the organic cell in the dark. The value of $\mathrm{n}$ used in the simulations varies between 1.2 and 2 . The ideality factor obtained by diode-equivalent model modeling for the inverted cell is shown in 
Figure 6. When $\mathrm{V}=\mathrm{V}_{\mathrm{OC}}$ the obtained ideality factor $\mathrm{n}=1.2$.

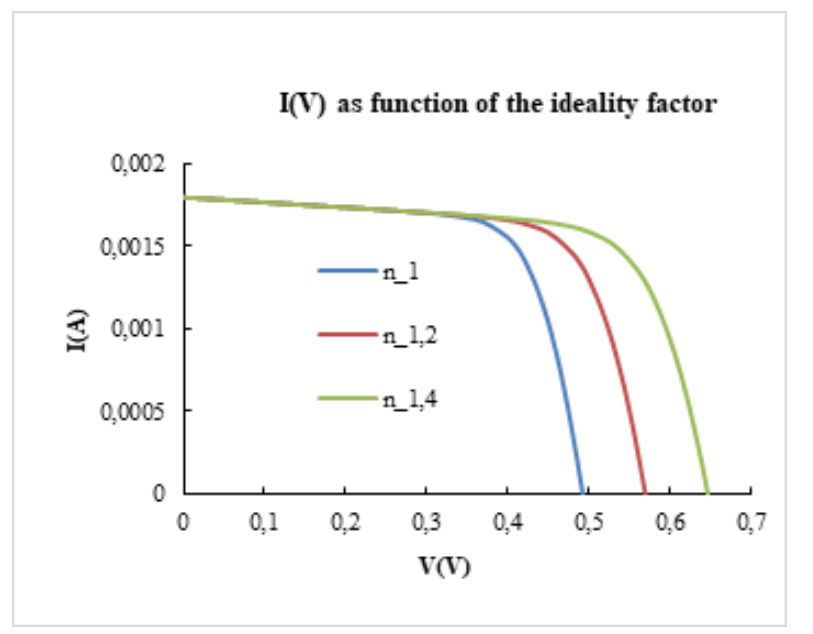

Fig. 6. Simulation of the I(V) characteristics as function of the ideality factor.

\subsection{Effect of the series resistance}

Series resistance is one of the parameters governing the operation of an organic solar cell. Figure 7 shows simulations of the effect of the variation of $R_{S}$ on the $\mathrm{J}-\mathrm{V}$ characteristics of the P3HT:PCBM inverted structure. The fill factor is significantly affected by increasing $R_{S}$ of the cell. The results of simulations show that the characteristic $J(V)$ with $R_{S}=10 \Omega$ is super imposed on the experimental curve.

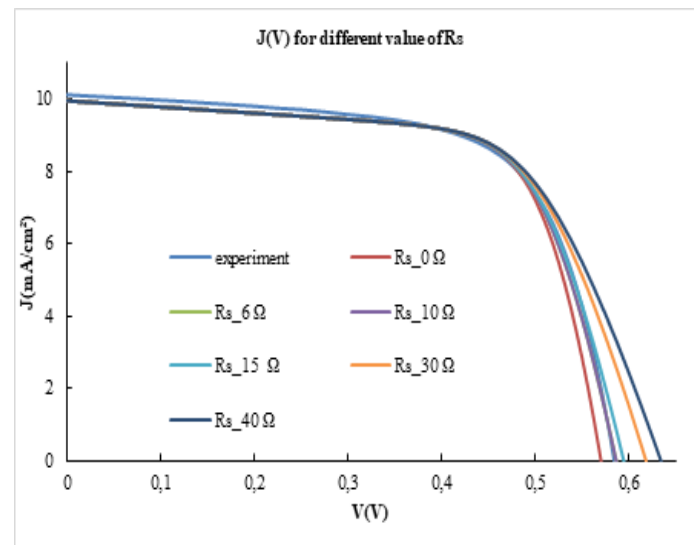

Fig. 7. Simulation of $J(V)$ characteristics as function of the series resistance.

\section{Simulation of the electrical parameters using GPVDM software}

Generally, there are six main important processes which might limit the power conversion efficiency of organic photovoltaic devices: light absorption in the film, free charge carrier generation, charge transport to the opposite electrodes and extraction by the electrodes, carrier recombination, architecture dimension, design of the device, and annealing temperature of the active layer or the final device.

The simulation of the GPVDM (General Purpose Photovoltaic Device Model) software makes it possible to predict the parameters of a photovoltaic cell according to the thickness of different layers. The modelled structure in this work is of the type ITO/ETL/P3HT:PCBM/HTL/Ag. The effect of the thickness of the different layers is given.

\subsection{Effect of the active layer thickness}

The $\mathrm{J}(\mathrm{V})$ characteristics as function of the thickness of the active layer are presented in Figure 8. The structure of the cell simulated is ITO/ZnO/P3HT:PCBM/ $/ \mathrm{V}_{2} \mathrm{O}_{5} / \mathrm{Ag}$. The best performance is obtained for cell with $200 \mathrm{~nm}$ of the active layer (P3HT:PCBM), $\mathrm{ZnO}(10 \mathrm{~nm})$ and $\mathrm{V}_{2} \mathrm{O}_{5}$ $(10 \mathrm{~nm}) \mathrm{PCE}=4.72 \%$.

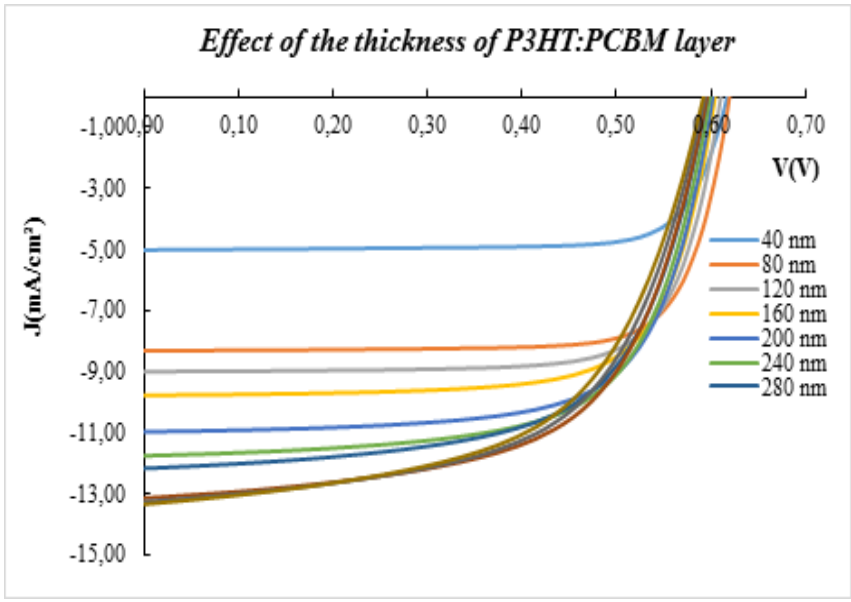

Fig.8. Effect of the thickness of P3HT:PCBM on the $\mathrm{J}-\mathrm{V}$ characteristics of the inverted cell using GPVDM.

\subsection{Effect of the Interfacial materials}

The interfacial layers were integrated into the organic devices to select the charges extracted from the active layer and to collect them at the electrodes according to 
their polarity. These interface layers are called electron transport layer (ETL) if they were at the interface of the cathode and hole transport layers (HTL) if they were at the interface with the anode. The interface materials in organic solar cells allow electrons and holes to be transported to the electrodes. The creation of an electron-hole pair occurs from a photon absorbed by the active layer. At the donor/acceptor interface of the active layer, the electron-hole pair dissociates to form two distinct charges. The electron is transported to the cathode and the hole is transported to the anode via the donor material.

The interface that is formed between the active layer and the electrodes is essential to obtain high performance and stable devices. The main function of the interface materials are as follows:

- Adjust the energy barrier between the active layer and the electrodes;

- Determine the polarity of the photovoltaic device;

- Limit physico-chemical reactions between the active layer and the electrodes;

- Transport the electrons and holes to the respective electrodes;

- Act as an optical spacer.

There are many types of interface materials such inorganic metal oxides, metal salts and small molecules. The metal oxides used as an electron transport layer in solar cells must be stable in air but especially as transparent as possible because they are on the side of the transparent electrode in the inverted configuration of the devices. The main oxides used as electron transport layer are: zinc oxide $(\mathrm{ZnO})$, aluminum-doped zinc oxide (AZO), titanium oxide (TiOx), tin oxide $\left(\mathrm{SnO}_{2}\right)$ and niobium pentoxide $\left(\mathrm{Nb}_{2} \mathrm{O}_{5}\right)$. The main oxide used as hole transport layer are: vanadium pentoxide $\left(\mathrm{V}_{2} \mathrm{O}_{5}\right)$, molybdenum trioxide $\left(\mathrm{MoO}_{3}\right)$, copper oxide $\left(\mathrm{Cu}_{2} \mathrm{O}\right)$, and molybdenum disulfide $\left(\mathrm{MoS}_{2}\right)$. The production of nanoparticles of dispersed oxides in a solvent makes it possible to manufacture devices with low annealing temperatures not exceeding $120^{\circ} \mathrm{C}$. Doping of the interfacial layers increases conductivity and therefore increases cell performance.

\subsubsection{Effect of the hole transport layer}

The use of inorganic hole transport layer improves stability of organic solar cells. GPVDM software is used to simulate the effect of different hole transport layer on the performance of the cells. The thickness of the hole transport layer is varied and the thickness of the other layers are fixed: $\mathrm{ZnO}(20 \mathrm{~nm})$ and P3HT:PCBM (200 nm). Different HTL are used such as: $\mathrm{V}_{2} \mathrm{O}_{5}, \mathrm{MoO}_{3}$, fullerene $\left(\mathrm{C}_{60}\right)$ and $\mathrm{P} 3 \mathrm{HT}$. Figure 9 shows the efficiency of the cell as function of the thickness of different hole transport layer. The structure simulated is ITO/ZnO/P3HT:PCBM/HTL/Ag. The obtained results show that the use of thin layer about $20 \mathrm{~nm}$ of $\mathrm{MoO}_{3}$ gives better power conversion efficiency, $\mathrm{PCE}=5 \%$.

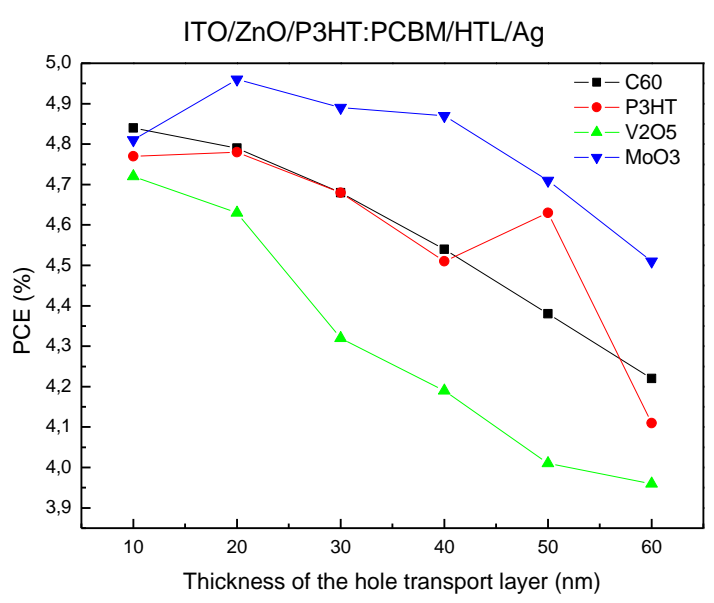

Fig.9. Effect of the thickness of different hole transport layer using GPVDM.

The effect of hole transport layer of a structure ITO/TiOx/P3HT:PCBM/HTL/Ag is presented in Figure 10. The thickness of the active layer (P3HT:PCBM) is $200 \mathrm{~nm}$, the electron transport layer titanium dioxide TiOx $(40 \mathrm{~nm})$, the thickness of ITO and $\mathrm{Ag}$ is $100 \mathrm{~nm}$, and the hole transport layer is variable from $10 \mathrm{~nm}$ to $60 \mathrm{~nm}$. The HTL used in the simulation are: $\mathrm{V}_{2} \mathrm{O}_{5}, \mathrm{Cu}_{2} \mathrm{O}$ and $\mathrm{MoS}_{2}$. Results show that the use of $20 \mathrm{~nm}$ of $\mathrm{CuO}_{2}$ as hole transport layer gives the best efficiency, $\mathrm{PCE}=5 \%$. 


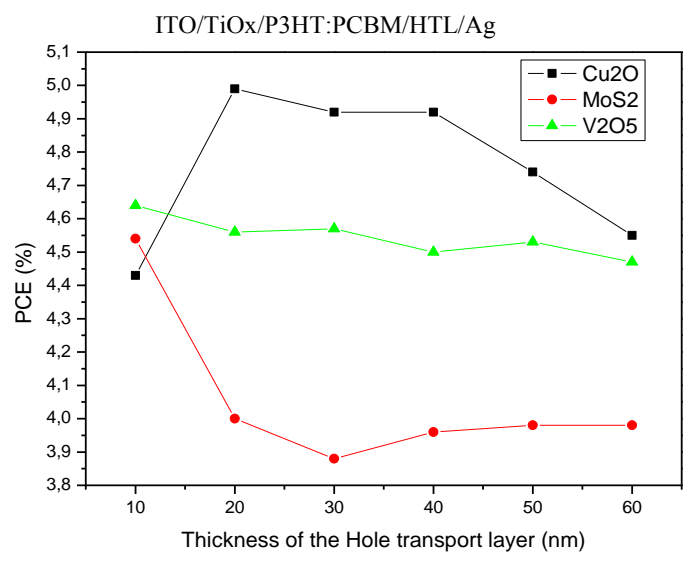

Fig.10. Effect of the thickness and the type of the hole transport layer using GPVDM software.

\subsubsection{Effect of the electron transport layer}

The cell simulated is of the type ITO/ETL/P3HT:PCBM/ $/ \mathrm{V}_{2} \mathrm{O}_{5} / \mathrm{Ag}$, the thickness of the electron transport layer (ETL) is varied, P3HT:PCBM $(200 \mathrm{~nm})$ and $\mathrm{V}_{2} \mathrm{O}_{5}(10 \mathrm{~nm})$. Different ETL are used such as: TiOx, $\mathrm{ZnO}, \mathrm{AZO}, \mathrm{PCBM}$ and $\mathrm{Nb}_{2} \mathrm{O}_{5}$. Figure 11 sows the power conversion efficiency of the organic cells as function of the thickness of the different electron transport layers. Cells with $10 \mathrm{~nm}$ of $\mathrm{Nb}_{2} \mathrm{O}_{5}, 10 \mathrm{~nm}$ of $\mathrm{V}_{2} \mathrm{O}_{5}$ and $200 \mathrm{~nm}$ of P3HT:PCBM give an efficiency of $4.73 \%, \mathrm{~J}_{\mathrm{SC}}=11.56 \%, \mathrm{~V}_{\mathrm{OC}}=0.6 \mathrm{~V}$ and $\mathrm{FF}=67.70 \%$. Cells with $40 \mathrm{~nm}$ of AZO give an efficiency of $4.79 \%, \mathrm{~J}_{\mathrm{SC}}=11.71 \mathrm{~mA} / \mathrm{cm}^{2}, \mathrm{~V}_{\mathrm{OC}}=0.6 \mathrm{~V}$ and $\mathrm{FF}=67.66 \%$. Low yields are obtained using organic materials such as PCBM as ETL.

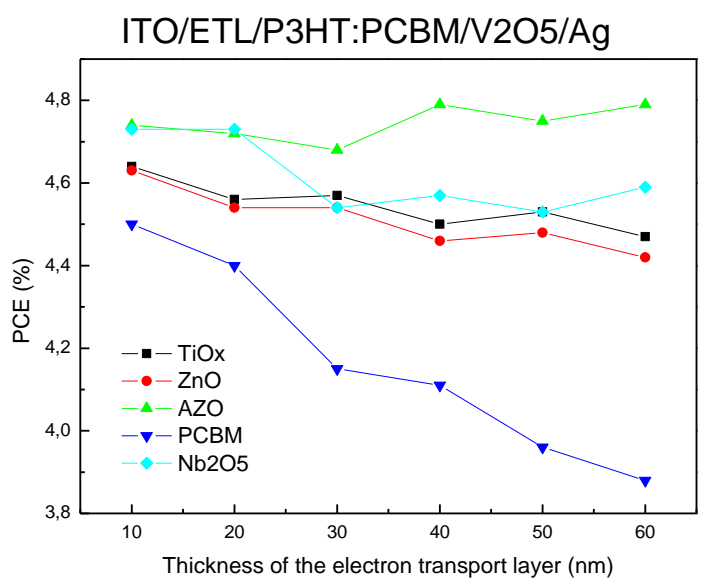

Fig.11. Effect of the electron transport layer in performance of the organic solar cells using GPVDM.

From Figure 9, Figure 10 and Figure 11, the best performance are obtained for following structure ITO $(100 \mathrm{~nm}) / \mathrm{AZO}(40 \mathrm{~nm}) / \mathrm{P} 3 \mathrm{HT}: \mathrm{PCBM}(200 \mathrm{~nm}) / \mathrm{Cu}_{2} \mathrm{O}$ $(20 \mathrm{~nm}) / \mathrm{Ag}(100 \mathrm{~nm}), \mathrm{PCE}=5 \%$.

The $J(V)$ characteristic of the optimized cell is given in Figure 12. The parameters of the cell are $\mathrm{PCE}=4.99 \%, \quad \mathrm{~V}_{\mathrm{OC}}=0.6 \mathrm{~V}, \quad \mathrm{~J}_{\mathrm{SC}}=12 \mathrm{~mA} / \mathrm{cm}^{2} \quad$ and $\mathrm{FF}=67.53 \%$.

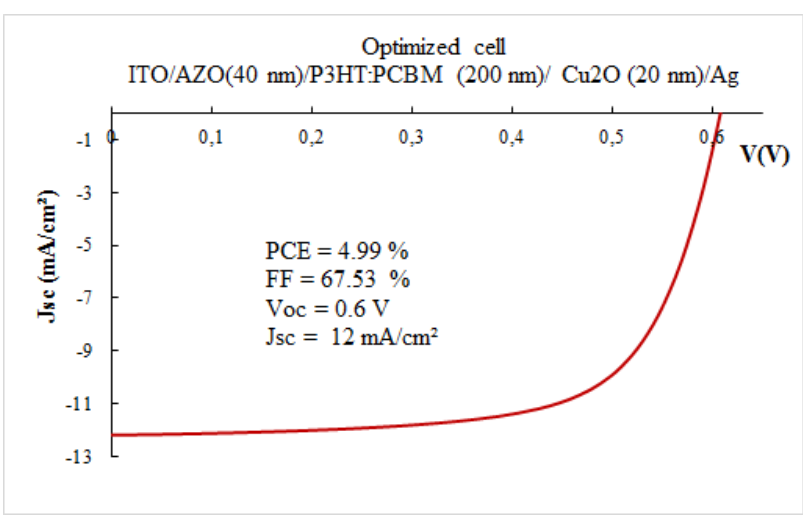

Fig.12. J-V characteristic of the optimized cell obtained by simulation under GPVDM.

Organic solar cells are sensitive to moisture, oxygen, and light. To improve performance and protect cells from ageing and degradation, an encapsulation of the cells is required. The addition of a fluorescent layer on the front of the cell should improve performance by converting part of the light 
spectrum into energy absorbed by the active layer. The fluorescence materials used in matrix of polymer can be used as encapsulation of the cells. Other solutions to improve stability of the cell is to use inorganic materials as hole transport layer or electron transport layer.

\section{Conclusion}

There are two different architectures for organic solar cells: standard and inverted. They differ according to the role of the lower electrode as a cathode or an anode. In the standard structure the holes go towards the ITO electrode while in the reverse structure the holes go towards the ITO electrode. Interface materials are located between the active layer and the electrodes. The advantages of these layers is the alignment of energy levels between the active layer, the electrodes and these interface materials in order to facilitate transport of charges to the electrodes and to minimize recombination. The objective of this paper is to obtain by simulation, the electrical characteristics and the behavior of a photovoltaic system by using QUCS simulation environment and GPVDM software, this according to the variations of the parameters of the model. The modeling results obtained on the QUCS environment using the singlediode model correspond to the experimental results when the Rs $=10 \Omega$; this allows us to conclude that the organic photovoltaic cell is equivalent to an electronic circuit composed of a current source, a diode, a series resistor and a parallel resistor, the calculated ideality factor of an organic solar cells is 1.2 which corresponds to recombination assisted by the traps levels. The open circuit voltage of the cell decrease when temperature increases. Using QUCS software, we can also simulate the performance of the cells according to the geometry of the electrodes and as a function of the active surface of the cell.

The use of GPVDM makes it possible to optimize the performance of organic photovoltaic cells, this by the choice of materials used as hole transport layer (HTL) and materials used for electron transport layer (ETL) as well as the thicknesses of the layers used. The power conversion efficiency of the structure ITO/AZO/P3HT:PCBM/ $/ \mathrm{V}_{2} \mathrm{O}_{5} / \mathrm{Ag}$, with the following thicknesses of the layers, AZO (40 nm), P3HT:PCBM $(200 \mathrm{~nm})$ and $\mathrm{V}_{2} \mathrm{O}_{5}(10 \mathrm{~nm})$ is $4.79 \%$.

In the case of cells with $\mathrm{ZnO}$ used as ETL the best efficiency is obtained for cells with $\mathrm{MoO}_{3}(20 \mathrm{~nm})$ used as $\mathrm{HTL}, \mathrm{PCE}=5 \%$. In the case of a structure ITO/TiOx/P3HT:PCBM/HTL/Ag, the best yield is given for cell using $\mathrm{CuO}_{2}(40 \mathrm{~nm})$ as $\mathrm{HTL}$, the obtained PCE is $=5 \%$. The comparison of the simulation results of the different structures allowed as to choose an optimized structure with suitable interface materials. The optimized cell is ITO/AZO $(40 \mathrm{~nm}) / \mathrm{P} 3 \mathrm{HT}: \mathrm{PCBM}(200 \mathrm{~nm}) / \mathrm{Cu}_{2} \mathrm{O}(20 \mathrm{~nm}) / \mathrm{Ag}$, with the following photovoltaic parameters: $\mathrm{PCE}=5 \%$, $\mathrm{V}_{\mathrm{OC}}=0.6 \mathrm{~V}, \quad \mathrm{~J}_{\mathrm{SC}}=12 \quad \mathrm{~mA} / \mathrm{cm}^{2}$ and $\mathrm{FF}=67.53 \%$. GPVDM is an interesting simulation tool, because it allows the optimization of the types of materials and their thicknesses before the production of the organic photovoltaic cell in order to have better yields with good stability.

\section{References}

[1] Balderrama, V.S. et al (2011). Influence of P3HT: PCBM blend preparation on the active layer morphology and cell degradation. Microelectronics Reliability, 51(3), 597-601.

[2] Spoltore, D. et al. (2015). Effect of molecular weight on morphology and photovoltaic properties in P3HT: PCBM solar cells. Organic Electronics, 21, 160-170.

[3] Lee, H.K.H, et al. (2018). The role of fullerenes in the environmental stability of polymer: fullerene solar cells. Energy \& Environmental Science, 11(2), 417-428.

[4] Kwon, OK et al. (2016). A high efficiency nonfullerene organic solar cell with optimized crystalline organizations. Advanced Materials, 28(5), 910-916.

[5] Banerjee, S. et al. (2016). Buffer layers in inverted organic solar cells and their impact on the interface and device characteristics: An experimental and modeling analysis. Organic Electronics, 37, 228-238.

[6] Laudani, A. et al. (2018). Irradiance intensity dependence of the lumped parameters of the three-diodes model for organic solar cells. Solar Energy, 163, 526-536.

[7] De Castro, F., et al. (2016). An in-depth analysis of the modelling of organic solar cells using multiple-diode circuits. Solar Energy, 135, 590597.

[8] López-Varo, P., et al. (2017). Boundary condition model for the simulation of organic solar cells. Organic Electronics, 48, 85-95. 
[9] Kim, C. H., et al. (2018). Lumped-element model of plasmonic solar cells. Solid-State Electronics, 147, 39-43.

[10] Gagliardi, A., et al. (2018). Simulation of charge Carrier mobility unbalance in organic solar cells. Organic Electronics, 59, 171-176.

[11] Suliman, R., et al. (2017). Modeling of organic solar cell using response surface methodology. Results in physics, 7, 2232-2241.

[12] Neupane, U., et al. (2017). Kinetic Monte Carlo modeling on organic solar cells: Domain size, donor-acceptor ratio and thickness. Nano energy, 35, 128-137.

[13] De Falco, et al. (2012). Multiscale modeling and simulation of organic solar cells. Computer Methods in Applied Mechanics and Engineering, 245, 102-116.

[14] De Falco, et al. (2010). Analytical and numerical study of photocurrent transients in organic polymer solar cells. Computer Methods in Applied Mechanics and Engineering, 199(25-28), 1722-1732.

[15] Knipp, D., et al. (2017). Towards 3D organic solar cells. Nano Energy, 31, 582-589.

[16] Scharber, M. C.,et al. (2013). Efficiency of bulk-heterojunction organic solar cells. Progress in polymer science, 38(12), 1929-1940.

[17] Sesa, E., et al. (2018). A building-block approach to the development of an equivalent circuit model for organic photovoltaic cells. Organic Electronics, 58, 207-215.

[18] Lee, S. J., et al. (2018). Role of geminate polaron-pair recombination on magnetoconductance in P3HT and PC71BM bulkheterojunction organic solar cells. Organic Electronics, 63, 384-391.

[19] Zuo, L., et al. (2014). Assessing the origin of the S-shaped I-V curve in organic solar cells: An improved equivalent circuit model. Solar Energy Materials and Solar Cells, 122, 88-93.

[20] Abbassi, R., et al. (2018). Identification of unknown parameters of solar cell models: A comprehensive overview of available approaches. Renewable and Sustainable Energy Reviews, 90, 453-474.

[21] Santiago, I., et al. (2018). Modeling of photovoltaic cell temperature losses: A review and a practice case in South Spain. Renewable and Sustainable Energy Reviews, 90, 70-89.

[22] Rhouma,et al. (2017). A simple method for extracting the parameters of the PV cell singlediode model. Renewable energy, 113, 885-894.

[23] Yahya-Khotbehsara, A., et al. (2018). A fast modeling of the double-diode model for PV modules using combined analytical and numerical approach. Solar Energy, 162, 403-409.

[24] Chin, V. J., et al. (2016). An accurate modelling of the two-diode model of PV module using a hybrid solution based on differential evolution. Energy conversion and management, 124, 42-50.

[25] Mao, P., et al. (2017). Junction diodes in organic solar cells. Nano energy, 41, 717-730.

[26] Mazhari, B. (2006). An improved solar cell circuit model for organic solar cells. Solar energy materials and solar cells, 90(7-8), 1021-1033.

[27] Dehghanzadeh, A.,et al. (2017). A novel approximate explicit double-diode model of solar cells for use in simulation studies. Renewable energy, 103, 468-477.

[28] Cheknane, A., et al. (2008). An equivalent circuit approach to organic solar cell modelling. Microelectronics Journal, 39(10), 1173-1180.

[29] Tada, K. (2017). Validation of opposed twodiode equivalent-circuit model for S-shaped characteristic in polymer photocell by low-light characterization. Organic Electronics, 40, 8-12.

[30] Romero, B., et al. (2012). Exact analytical solution of a two diode circuit model for organic solar cells showing S-shape using Lambert Wfunctions. Solar Energy, 86 (10), 3026-3029.

[31] Romero, B., et al. (2014). Circuital modelling of S-shape removal in the current-voltage characteristic of TiOx inverted organic solar cells through white-light soaking. Organic Electronics, 15(12), 3546-3551.

[32] Lattante, S.,et al. (2011). Study of the series resistance evolution in organic solar cells by use of the Lambert W function. Synthetic Metals, 161(11-12), 949-952.

[33] Street, R. A., et al. (2011). Influence of series resistance on the photocurrent analysis of organic solar cells. Organic Electronics, 12(2), 244-248.

\section{Creative Commons Attribution License 4.0} (Attribution 4.0 International, CC BY 4.0)

This article is published under the terms of the Creative Commons Attribution License 4.0

https://creativecommons.org/licenses/by/4.0/deed.en_US 